\title{
Cytopathological Heterogeneity of Circulating Tumor Cells in Non-metastatic Esophageal Adenocarcinoma
}

\author{
JASMINA KUVENDJISKA ${ }^{1,2}$, MARTHA B. PITMAN ${ }^{3}$, VERENA MARTINI ${ }^{1,2}$, CLARA BRAUN $^{2}$, \\ KIM GREBE $^{2}$, SYLVIA TIMME ${ }^{2,4}$, STEFAN FICHTNER-FEIGL ${ }^{1,2}$, TORBEN GLATZ ${ }^{5}$, \\ CLAUDIA SCHMOOR $^{6}$, JESSICA GUENZLE ${ }^{1,2}$, JENS HOEPPNER ${ }^{1,2}$ and BIRTE KULEMANN ${ }^{1,2}$ \\ ${ }^{1}$ Department of General and Visceral Surgery, Medical Center - University of Freiburg, Freiburg, Germany; \\ ${ }^{2}$ Faculty of Medicine, Albert-Ludwigs-University of Freiburg, Freiburg, Germany; \\ ${ }^{3}$ Department of Pathology \& Andrew L. Warshaw, MD Institute for Pancreatic Cancer Research, \\ Massachusetts General Hospital/ Harvard Medical School, Boston, MA, U.S.A.; \\ ${ }^{4}$ Institute for Surgical Pathology, and Tumorbank Comprehensive Cancer Center, \\ Medical Center - University of Freiburg, Freiburg, Germany; \\ ${ }^{5}$ Department of General, Visceral and Vascular Surgery, \\ Marien Hospital Herne, Faculty of Medicine, Bochum, Germany; \\ ${ }^{6}$ Clinical Trials Unit, Faculty of Medicine and Medical Center, University of Freiburg, Freiburg, Germany
}

\begin{abstract}
Background/Aim: The presence of circulating tumor cells (CTC) has been reported to have an impact on prognosis in different tumor entities. Little is known about CTC morphology and heterogeneity. Patients and Methods: In a multicenter setting, pre-therapeutic peripheral blood specimens were drawn from patients with non-metastatic esophageal adenocarcinoma (EAC). CTCs were captured by size-based filtration (ScreenCell $\left.{ }^{\circledR}\right)$, subsequently Giemsa-stained and evaluated by two trained readers. The isolated cells were categorized in groups based on morphologic criteria. Results: Small and large single CTCs, as well as CTC-clusters, were observed in $69.2 \%$ ( $n=81)$ of the 117 specimens; small CTCs were observed most frequently (59\%; $n=69)$, followed by large CTCS $(40 \% ; n=47)$ and circulating cancer-associated macrophage-like cells (CAMLs; $34.2 \%, n=40$ ). Clusters were rather rare $(12 \% ; n=14)$. CTC/CAML were heterogeneous in the cohort, but also within one specimen. Neither the presence of the CTC subtypes/CAMLs nor the exact cell count were associated with the primary clinical TNM stage. Conclusion:
\end{abstract}

This article is freely accessible online.

Correspondence to: Dr. Jasmina Kuvendjiska and PD Dr. Birte Kulemann, Department of General and Visceral Surgery, Hugstetter Straße 55, 79106 Freiburg, Germany. Tel: +49 76127024010, e-mail: jasmina.kuvendjiska@uniklinik-freiburg.de (JK); e-mail: birte.kulemann@uniklinik-freiburg.de (BK)

Key Words: Esophageal cancer adenocarcinoma, circulating tumor cells, CAML, cytopathology, heterogeneity.
Morphologically heterogenic CTCs and CAMLs are present in patients with non-metastatic, non-pretreated EAC.

Over the past decades the incidence of esophageal squamous cell carcinoma has decreased significantly in the U.S. and Europe. At the same time, the incidence of adenocarcinoma (EAC) has increased rapidly, especially among men (1). Although overall survival has improved over the years thanks to new treatment strategies, the prognosis is still limited (2). We still lack tools for better pre-therapeutic risk-stratification for cancer recurrence, which would enable us to design patientadapted treatment strategies. Currently, treatment decisions are being made based on CT-scans, endoscopic findings, endoscopic ultrasound and tumor biopsy. This momentary pretherapeutic "tumor-image" of the patient does not adequately reflect the actual tumor biology and aggressiveness. More than $50 \%$ of the patients initially considered curable will eventually relapse or develop metastasis after complete resection of the tumor (3). This relapse could be due to clinically invisible distant micro-metastases and tumor dissemination at an early time point, or due to lack of treatment response.

A promising tool to evaluate these occult metastases for risk stratification and treatment surveillance is the use of liquid biopsy (4). Liquid biopsy summarizes the analysis of tumor cells and tumor-derived products in body fluids, like circulating tumor cells (CTC) (5-7), circulating tumor DNA (ctDNA) (8, 9) and extracellular vesicles (EVs) (10-12). In the case of EAC, there are very limited studies available regarding CTC presence and their significance in general $(5,13-16)$. CTC have been found in about $20 \%$ of patients using epithelial surface antigen (EpCAM)-dependent isolation devices in EAC. These patients 
showed significantly shorter relapse-free and overall survival (OS) in an obsolete surgery-alone treatment protocol. In addition, multivariate analysis identified the presence of CTC as a strong, independent prognostic marker of tumor recurrence and overall survival (5).

Furthermore, the presence of cancer-associated macrophage-like cells (CAML) has been described (17) in blood samples of patients with breast, pancreatic, and prostate cancers. It is hypothesized that CAMLs originate from the local tumor-associated macrophages (TAMs) and have spread into the blood circulation $(17,18)$. The increased CAML size and higher levels of CAML is correlated with shorter progression-free survival and worse OS in untreated breast cancer patients $(19,20)$.

CTC heterogeneity has been shown and described in other tumor entities (21-24). We also found a diverse population of CTC in a pilot study of 20 EAC patients undergoing multimodal treatment (14). The exact relevance of the CTC-subpopulations for the prognosis estimation is yet to be discovered.

The aim of this study was to assess the morphological presence, diversity and morphological subgroups of circulating cells in patients with non-metastatic non-treated EAC. To our knowledge no study has investigated the morphologic diversity of CTC in this entity.

\section{Patients and Methods}

Patients and study design. We included patients with diagnosed adenocarcinoma of the esophagus in a non-metastatic state $(\mathrm{cT} 1 \mathrm{~N}+$ $\mathrm{M} 0$ or cT2-4a N0/N+, M0) and before the initiation of any treatment. Every patient was qualified for multimodal treatment and was considered curable. All participants gave full informed consent for material, data acquisition and the following experiments. The study was approved by the Ethics Committee of the Albert-Ludwigs University Freiburg (315/15 FF-MC), Freiburg, Germany. Patients had no history of squamous, adenosquamous or other non-adenocarcinoma tumors. Also, the patients had no history of chemotherapy for gastrointestinal cancer or no prior abdominal or thoracic radiotherapy.

The blood specimens were collected in transfix tubes (Circulating Tumor Cell TransFix/EDTA Vacuum Blood Collection Tubes 9ml, Firma: Cytomark, Caltag Medsystems Ltd, Buckingham, UK) right after the study enrolment. The tubes were sent within 24 hours after blood draw to the CTC laboratory at the Medical Center University of Freiburg.

CTC analysis. The processing of the blood samples was performed in the laboratory of the University Hospital Freiburg within 96 hours after blood draw from the patient. The CTC enrichment was performed by cell size-based filtration using the ScreenCell ${ }^{\circledR}$ Cyto kit (ScreenCell, Sarcelles, France) as we have reported previously (14). This represents a surface marker independent CTC enrichment method. The SceenCell ${ }^{\circledR}$ system is fitted with microfilters that capture the cells on small metal-rimmed filters via low-pressure vacuum-filtration. The blood samples were processed through two ScreenCell ${ }^{\circledR}$ filtration devices (Paris, France), according to the manufacturer's instructions ( $3 \mathrm{ml}$ blood per filtration device). The filter was then left to dry at room temperature and was subsequently
Table I. Patient characteristics and cTNM stage.

\begin{tabular}{lc}
\hline Number of patients $(\mathrm{n})$ & 117 \\
Gender (male/female) $\mathrm{n}(\%)$ & $103 / 14(88.0 / 12.0)$ \\
Age in years (mean) & 62.6 \\
BMI in kg/m ${ }^{2}$ (mean) & 27.7 \\
Clinical TNM stage, $\mathrm{n}(\%)$ & \\
cT-Stage & \\
T1 & $2(1.7)$ \\
T2 & $20(17.2)$ \\
T3 & $85(73.3)$ \\
T3-T4 & $3(2.6)$ \\
T4 & $6(5.2)$ \\
Tx & 1 \\
cN-Stage & \\
N0 & $30(25.9)$ \\
N+ & $86(74.1)$ \\
Nx & 1 \\
cM-Stage & \\
M0 & $117(100)$ \\
\hline
\end{tabular}

BMI: Body mass index; T- Stage: size of the primary tumor; N-Stage: degree of spread in regional lymph nodes; M-Stage: presence of distant metastasis.

stained with a standard May-Grünwald Giemsa staining. Every CTC was photographed, documented and categorized by two trained readers on bright field without immunofluorescence staining as previously described (25). Questionable interpretations were evaluated again until consensus was reached and were analyzed by two cytopathologists for verification. Circulating endothelial cells (CECs) also were classified by overall impression (negative, suspicious, or positive). The cut off for small CTC was set at 16 $\mu \mathrm{m}$. Cells below this size were not counted as potential CTCs. The category "large CTC" was set for cells $25 \mu \mathrm{m}$ or larger due to the gross quality and size across all specimens and according to previous descriptions (26). Clusters were rather smaller epithelial cells that occurred in clusters. The category CAML was included as described by Adams et al. as large cells $>25 \mu \mathrm{m}$ with multilobulated nuclei and a relatively low NC ratio (17). Differences were analyzed based on the initial clinical TNM classification (27).

Statistics. No formal sample size calculation was performed. All analyses were performed using SAS 9.3. Data were analyzed descriptively. Categorical data were summarized by absolute and relative frequencies. Continuous data were summarized by mean, standard deviation, median, quartiles and range. The relationship between the prevalence of CTC and the $\mathrm{cT}$ and $\mathrm{cN}$ status were analyzed. The probability of any CTC was statistically compared between patients with cT1-2 versus cT3-4 and between patients with cN0 versus $\mathrm{cN}+$ using chi-square tests each at a two-sided significance level alpha of $5 \%$. The probability of any CTC was estimated with $95 \%$ confidence intervals in the whole study population and in subgroups defined by $\mathrm{cT}$ and by $\mathrm{cN}$.

\section{Results}

Patients. We included 117 patients with non-metastatic EAC before the initiation of treatment. In two cases the exact cT and $\mathrm{cN}$ - stage were unknown. Therefore, these patients were 


\section{Small CTC}

- $\quad$ Enlarged nuclei $(\geq 16-24 \mu \mathrm{m})$

- Hyperchromatic nuclei

- Irregular nuclear borders

- $\quad$ Increased NC ratio

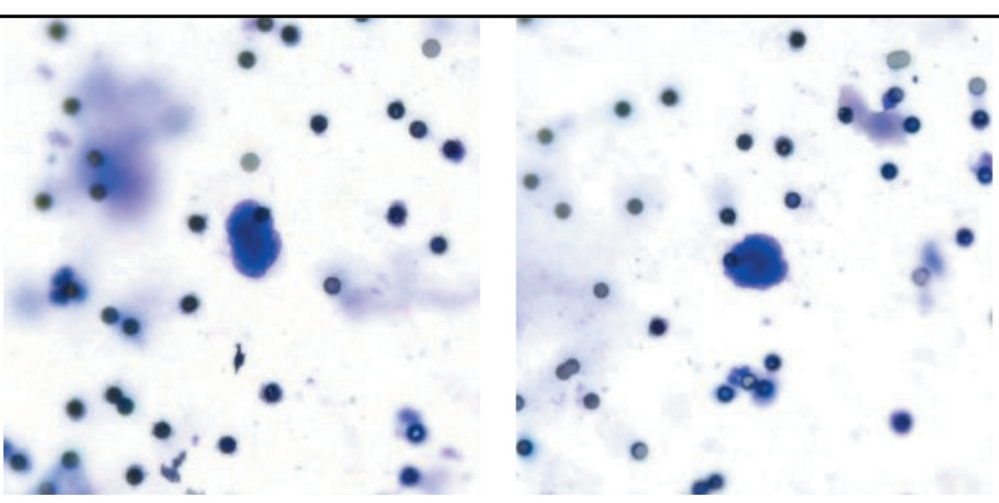

\section{Large CTC}

- $\quad$ Enlarged nuclei $(\geq 25 \mu \mathrm{m})$

- Hyperchromatic nuclei

- Irregular nuclear borders

- Increased NC ratio

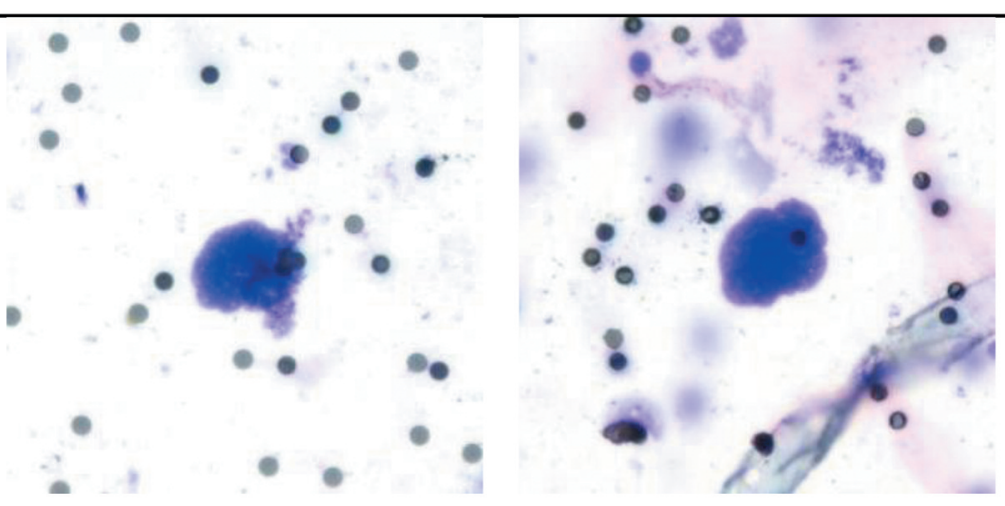

\section{Cluster CTC}

- Anisonucleosis

- Hyperchromatic nuclei

- Irregular nuclear borders

- Increased isolated nuclei ( $>2$ pore size)

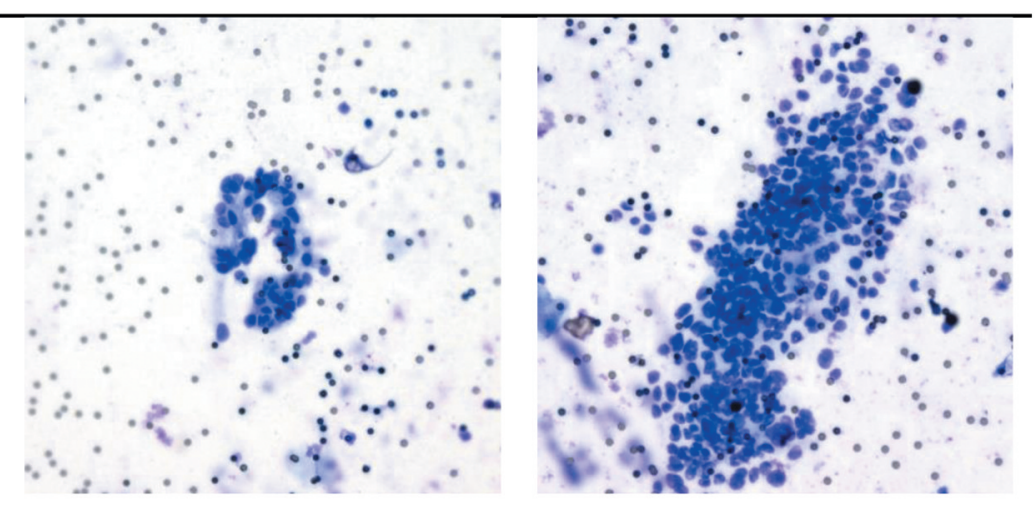

\section{CAML}

- $\quad$ Enlarged, often multilobulated nuclei or separated polymorphic nuclei

- Large remarkable cytoplasm

- Relatively low NC ratio

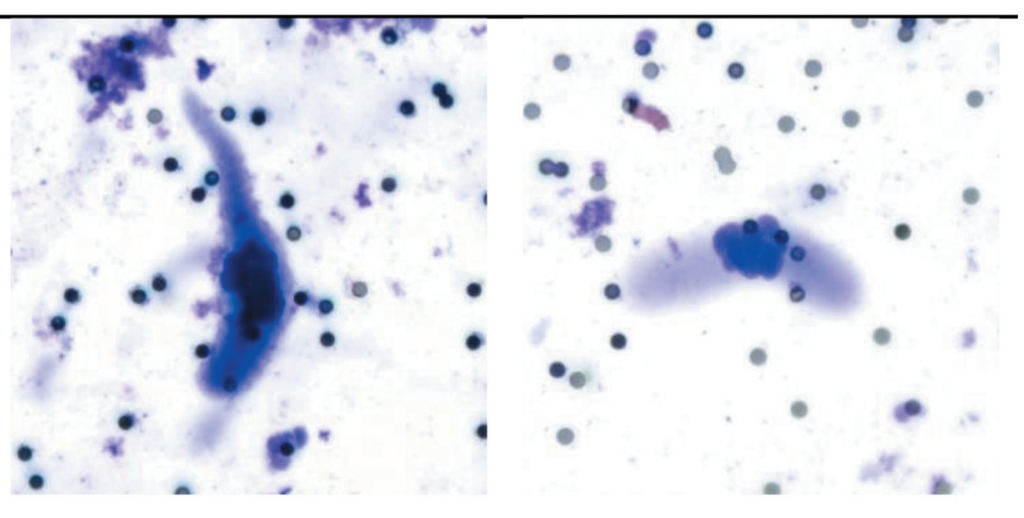

Figure 1. CTC categorization: Exemplary pictures of the CTC categories. Cells were isolated by ScreenCell ${ }^{\circledR}$, May-Grünwald Giemsa staining (20x magnified). Filter pores $(7.5 \mu \mathrm{m})$. 
excluded from the statistical analysis related to cTNM. The average age was 62.5 years and most of the patients were male. The patient characteristics are presented in Table I. In terms of the clinical TNM stage, $73.9 \%(n=85)$ of the studypopulation had a cT3 stage and had tumor-positive lymph nodes $(\mathrm{cN}+)$ on pre-therapeutic imaging. No patient had clinical signs of metastasis (cM0).

CTC categorization. Epithelioid cells with enlarged (>16 $\mu \mathrm{m})$, irregular, hyperchromatic nuclei and increased nuclear to cytoplasmic (NC) ratio were counted as CTCs. Overall, $69.2 \%$ [ $n=81,95 \%$ confidence interval (CI) $(60.9 \%, 77.6 \%)]$ of all specimens were CTC positive.

After identification and documentation of all CTC suspected cells in all patients, we determined four categories of cells based on morphologic features: small and large single-CTCs, clusterCTCs and circulating cancer-associated macrophage-like cells (CAML). A summary of the morphologic characteristics and exemplary pictures are shown in Figure 1. Fifty-nine percent $(n=69)$ of the patients had small CTCs with nuclei $\geq 16-24 \mu \mathrm{m}$ and $40 \%(n=47)$ had large CTCs with nuclei $\geq 25 \mu \mathrm{m}$. Both subpopulations had an increased $\mathrm{NC}$ ratio with a very small rim of cytoplasm. Twelve $\%(n=14)$ of the patients were positive for cluster CTCs, which showed a very variable cell count. Furthermore, we identified the presence of CAMLs in $34.2 \%$ $(n=40)$ of the patients. Some cells were poorly preserved and were not included in the analysis due to lacking cytomorphological features: $75.2 \%(n=88)$ had single CTC suspicious cells (median of 1 cells $/ 3 \mathrm{ml})$ and $65.8 \%(\mathrm{n}=77)$ naked nuclei without visible cytoplasm (median of 1 cells $/ 3 \mathrm{ml}$ ).

The CTC-positive patients showed relatively low counts of all types of CTC/CAML: they had a mean of 6.38 (median 3) small CTCs, a mean of 2.40 (median 1) large CTCs and a mean of 7.48 (median 4) CAML in 3 ml EDTA blood (one filter). The described CTCs, Cluster-CTC and CAML subtypes were observed not only between different patients but regularly within one specimen from the same patient (Figure 2).

CTC association with cTNM-status. The positivity for any type of CTC was not related with the pre-therapeutic T stage $(61.9 \%, 95 \% \mathrm{CI}=41.1-82.7 \%$, in 21 patients with cT1cT2 and $70.2 \%, 95 \% \mathrm{CI}=61.0-79.5 \%$ in 94 patients with cT3cT4, $\mathrm{p}=0.46)$ or $\mathrm{N}$-stage $(73.3 \%, 95 \% \mathrm{CI}=57.5-89.2 \%$, in 30 patients with $\mathrm{cN} 0$ and $67.1 \%, 95 \% \mathrm{CI}=57.1-77.1 \%$, in 85 patients with $\mathrm{cN}+, \mathrm{p}=0.52)$. Furthermore, the number of CTCs showed no relevant differences between the cT stages and $\mathrm{cN}$ - stages (Tables II and III). Two patients were excluded from this statistical analysis, since the exact cTNM stage was not determined. Single patients with a higher cT stage 3-4 had higher maximum CTC counts compared to patients with lower cT stage 1-2, but no relevant difference in mean numbers was observed.

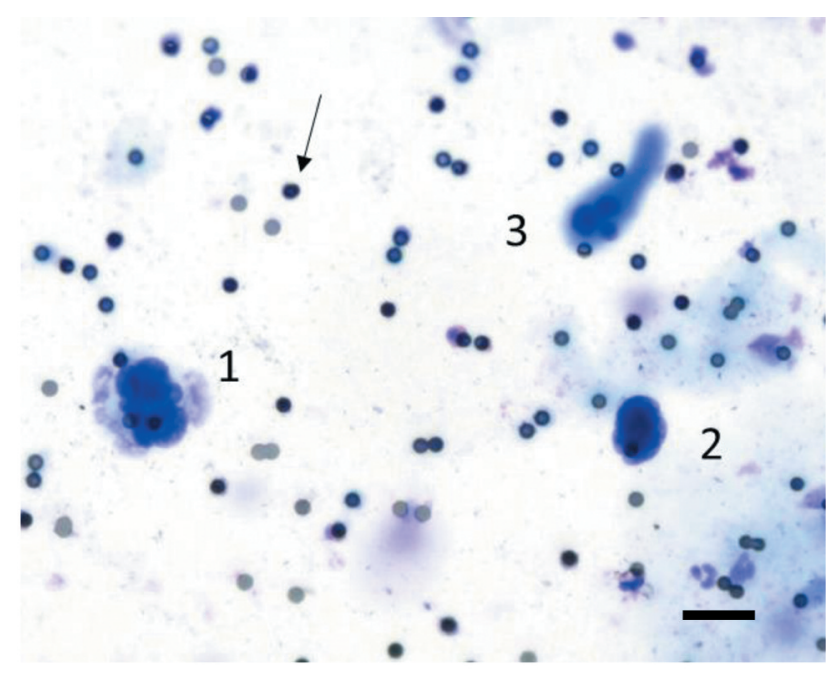

Figure 2. Representative picture of a large CTC (1), small CTC (2) and CAML (3) in the same sample. Cells were isolated by ScreenCell ${ }^{\circledR}$, May-Grünwald Giemsa staining (20× magnified). Filter pores $(7.5 \mu \mathrm{m})$ marked with simple black arrow, Scale bar $30 \mu \mathrm{m}$.

Single patients with clinically apparent lymph node involvement $\mathrm{N}+$ had higher maximum CTC and CAML counts compared to patients with no evidence of clinically proven pre-therapeutic lymph node involvement N0 (Table III). Again, no relevant difference in mean numbers was present

\section{Discussion}

The present study shows for the first time the cytomorphology of CTCs in over one hundred patients with non-metastatic adenocarcinoma of the esophagus (EAC). After evaluating all specimens, we determined the presence of four different typical subtypes of cancer-associated cells: we defined the groups of small (16-24 $\mu \mathrm{m})$ and large $(\geq 25$ $\mu \mathrm{m})$ CTCs, clusters of different sizes and CAMLs (circulating cancer-associated macrophage-like cells). CAMLs were previously morphologically described and characterized by Adams et al. using immunofluorescence and morphology (17). Although the CAMLs are thought not to be cancer cells, we listed them next to the CTCs, considering that they originate from the tumor site and are believed to interact with the CTCs (17). The detection of CAMLs is of significance, since there is evidence of high prevalence in different cancer types even in early stages (20). Moreover, increased size of these cells and higher count of CAMLs have been found to be associated with worse progressionfree and overall survival in patients with breast cancer (19, 20 ). In our cohort, $34.2 \%$ of the patients were positive for 
Kuvendjiska et al: CTC-Heterogeneity in Esophageal Adenocarcinoma

Table II. Number of CTCs and CAML in correlation with cT-stage (CTC per Filter $=3 \mathrm{ml}$ blood).

\begin{tabular}{llccccrr}
\hline cT & $\mathrm{n}$ & Variable & Mean & Std Dev & Minimum & Median & Maximum \\
\hline T1-T2 & 21 & Small CTC & 2.33 & 4.75 & 0 & 0 & 1 \\
& 21 & Large CTC & 0.85 & 1.59 & 0 & 0 \\
& 21 & CAML & 3.05 & 7.11 & 0 & 0 & 3 \\
T3-T4 & 94 & Small CTC & 2.61 & 4.49 & 0 & 0 & 30 \\
& 94 & Large CTC & 0.99 & 1.92 & 0 & 0 & 9 \\
& 94 & CAML & 2.45 & 5.81 & 0 & 0 & 36 \\
\hline
\end{tabular}

T- Stage: Size of the primary tumor; CTC: circulating tumor cell; CAML: cancer-associated macrophage-like cells.

Table III. Number of CTCs and CAML in correlation with $c N$-stage (CTC per Filter $=3 \mathrm{ml}$ blood).

\begin{tabular}{ccccccrr}
\hline $\mathrm{cN}$ & $\mathrm{n}$ & Variable & Mean & Std Dev & Minimum & Median & Maximum \\
\hline N0 & 30 & Small CTC & 3.20 & 3.85 & 0 & 2 & 14 \\
& 30 & Large CTC & 0.73 & 1.08 & 0 & 0 & 4 \\
& 30 & CAML & 2.27 & 3.91 & 0 & 0 & 1 \\
$\mathrm{~N}+$ & 85 & Small CTC & 2.33 & 4.73 & 0 & 0 & 33 \\
& 85 & Large CTC & 1.04 & 2.06 & 0 & 0 & 36 \\
\hline
\end{tabular}

N-Stage: Degree of spread in regional lymph nodes; CTC: circulating tumor cell; CAML: cancer-associated macrophage-like cells.

CAML. The impact of the here-described CAMLs on survival or their possible use as treatment surveillance parameter remains to be determined after clinical follow-up of a minimum of 3 years.

Overall, we found quite low numbers of CTCs and CAMLs in our patient cohort. This is expected, considering the generally lower CTC-detection rate in gastrointestinal cancers $(18,28)$ and especially the non-metastatic state of our patients (16). The group of small CTCs was most frequently found in our patient cohort. We - as previously reported (25) - defined the cutoff of $16 \mu \mathrm{m}$-which is double the size of a filter pore to ensure the most complete inclusion of possible CTCs. Since these cells are, however, relatively small compared to other CTC, it is unclear if these are true CTCs or undetermined circulating cells. Other groups describe CTCs of this size (29, 30). The relevance of the different morphologically diverse CTC subtypes for overall and progression-free survival remains to be discovered in further analysis.

Additionally, we observed some unidentified cells with damaged cytoplasm, which could be caused by the transport between the site of the blood draw and the study center. This also could influence the number of detected CTCs and could lead to false-low CTC counts across the specimens.

In this study, we described every observed CTC without the use of any cut-off for CTC positivity. Our intention was purely the cytomorphological evaluation of the CTCs. This may very well include an irrelevant fraction of circulating cells. Interestingly, the presence and the actual count of the CTCs and CAMLs showed no association to the clinical
TNM stage. Regarding the connection of CTC to the cTNM stage there are contradictory reports concerning other tumor entities. In patients with small cell lung cancer, higher numbers of CTC were observed in patients with lymph node metastasis (N1-3) and III/IV stage of TNM (31). Similar results have been found in patients with colorectal and gastric cancer $(28,32,33)$. A meta-analysis of 18 articles on CTCs in esophageal carcinoma has also shown a significant association with TNM staging (34). We must take into consideration, though, that these studies used the postoperative TNM classification, the pTNM stage for the analysis. However, in patients with squamous-cell carcinoma of the esophagus and colorectal carcinoma a significant correlation of the CTCs was described only with the N stage but not with the $\mathrm{T}$ stage $(35,36)$. Also, there are reports suggesting no significant correlation between TNM stage in patients with colorectal carcinoma (37). The association of CTC and cTNM and pTNM is thus yet to be determined.

The results presented here are based on the morphologic appearance of the cells using bright field microscopy and need to be evaluated with further immunofluorescence labelling. The CTC enrichment by size surely has its weaknesses due to the higher probability of false positive results in comparison to methods using cell surface antigens. At the same time this is also a strength, since it allows us a particularly good and detailed overview of the complete picture of likely circulating tumor-associated cells. Further analysis with immunofluorescence labelling and genetic singe-cell characterization of the CTCs are planned. 
Most importantly, long-term prospective studies are needed to track the changes in CTCs and CAMLs over the treatment time in patients with EAC. This will hopefully show us the true potential of the separate CTCsubpopulations and CAMLs in treatment surveillance and clarify their significance as prognostic markers.

\section{Conflicts of Interest}

J.K. received travel funding from ScreenCell ${ }^{\circledR}$ to the TriCon meeting 2019. The funders had no role in the design of the study; in the collection, analyses, or interpretation of data; in the writing of the manuscript, or in the decision to publish the results.

\section{Authors' Contributions}

Conceptualization, J.K., B.K. and J.H.; methodology, B.K., T.G. and V.M.; validation, M.P. and S.T.; formal analysis, C.S.; investigation, C.B. , K.G. and J.G.; resources, B.K., S.F.F. and J.H.; data curation, C.B. and K.G..; writing - original draft preparation, J.K.; writing review and editing, B.K., S.F.F., T.G., C.S., M.P. and J.H.; visualization, J.K.; supervision, B.K.; project administration, BK.; funding acquisition, B.K.

\section{Funding}

This research was funded by the Else Kröner-Fresenius-Stiftung grant number 2018_A74 and B.K. was funded by the BertaOttenstein-Programme for Advanced Clinician Scientists, Faculty of Medicine, University of Freiburg.

\section{References}

1 He H, Chen N, Hou Y, Wang Z, Zhang Y, Zhang G and Fu J: Trends in the incidence and survival of patients with esophageal cancer. A SEER database analysis. Thorac Cancer, 2020. PMID: 32154652. DOI: 10.1111/1759-7714.13311

2 Haiyu Z, Xiaofeng P, Xiangqiong M, Junlan Q, Xiaobin Z, Shuncong W, Huanhuan S and Haiqing M: Incidence and survival changes in patients with esophageal adenocarcinoma during 1984-2013. BioMed Res Int 2019: 7431850, 2019. PMID: 31915702. DOI: 10.1155/2019/7431850

3 Shapiro J, van Lanschot JJB, Hulshof MCCM, van Hagen P, van Berge Henegouwen MI, Wijnhoven BPL, van Laarhoven HWM, Nieuwenhuijzen GAP, Hospers GAP, Bonenkamp JJ, Cuesta MA, Blaisse RJB, Busch ORC, Kate FJW ten, Creemers G-JM, Punt CJA, Plukker JTM, Verheul HMW, Bilgen EJS, van Dekken H, van der Sangen MJC, Rozema T, Biermann K, Beukema JC, Piet AHM, van Rij CM, Reinders JG, Tilanus HW, Steyerberg EW and van der Gaast A: Neoadjuvant chemoradiotherapy plus surgery versus surgery alone for oesophageal or junctional cancer (CROSS). Long-term results of a randomised controlled trial. Lancet Oncol 16: 1090-1098, 2015. PMID: 26254683. DOI: 10.1016/S1470-2045(15)00040-6

4 Krebs MG, Renehan AG, Backen A, Gollins S, Chau I, Hasan J, Valle JW, Morris K, Beech J, Ashcroft L, Saunders MP and Dive C: Circulating tumor cell enumeration in a phase II trial of a four-drug regimen in advanced colorectal cancer. Clin Colorectal
Cancer 14: 115-22.e1-2, 2015. PMID: 25680623. DOI: 10.1016/j.clcc.2014.12.006

5 Reeh M, Effenberger KE, Koenig AM, Riethdorf S, Eichstadt D, Vettorazzi E, Uzunoglu FG, Vashist YK, Izbicki JR, Pantel K and Bockhorn M: Circulating tumor cells as a biomarker for preoperative prognostic staging in patients with esophageal cancer. Ann Surg 261: 1124-1130, 2015. PMID: 25607767. DOI: 10.1097/SLA.0000000000001130

6 Zheng X, Fan L, Zhou P, Ma H, Huang S, Yu D, Zhao L, Yang S, Liu J, Huang A, Cai C, Dai X and Zhang T: Detection of circulating tumor cells and circulating tumor microemboli in gastric cancer. Transl Oncol 10: 431-441, 2017. PMID: 28448959. DOI: $10.1016 /$ j.tranon.2017.02.007

7 Giuliano M, Giordano A, Jackson S, Giorgi U de, Mego M, Cohen EN, Gao H, Anfossi S, Handy BC, Ueno NT, Alvarez RH, Placido S de, Valero V, Hortobagyi GN, Reuben JM and Cristofanilli M: Circulating tumor cells as early predictors of metastatic spread in breast cancer patients with limited metastatic dissemination. Breast Cancer Res 16: 440, 2014. PMID: 25223629. DOI: 10.1186/s13058-014-0440-8

8 Creemers A, Krausz S, Strijker M, van der Wel MJ, Soer EC, Reinten RJ, Besselink MG, Wilmink JW, van de Vijver MJ, van Noesel CJM, Verheij J, Meijer SL, Dijk F, Bijlsma MF, van Oijen MGH and van Laarhoven HWM: Clinical value of ctDNA in upper-GI cancers. A systematic review and meta-analysis. Biochim Biophys Acta Rev 1868(2): 394-403, 2017. PMID: 28801248. DOI: 10.1016/j.bbcan.2017.08.002

9 Kato S, Okamura R, Baumgartner JM, Patel H, Leichman L, Kelly K, Sicklick JK, Fanta PT, Lippman SM and Kurzrock R: Analysis of circulating tumor DNA and clinical correlates in patients with esophageal, gastroesophageal junction, and gastric adenocarcinoma. Clin Cancer Res 24: 6248-6256, 2018. PMID: 30348637. DOI: $10.1158 / 1078-0432$.CCR-18-1128

10 Klump J, Phillipp U, Follo M, Eremin A, Lehmann H, Nestel S, Bubnoff $\mathrm{N}$ von and Nazarenko I: Extracellular vesicles or free circulating DNA. Where to search for BRAF and cKIT mutations? Nanomedicine 14: 875-882, 2018. PMID: 29288729. DOI: $10.1016 /$ j.nano.2017.12.009

11 Vagner T, Spinelli C, Minciacchi VR, Balaj L, Zandian M, Conley A, Zijlstra A, Freeman MR, Demichelis F, De S, Posadas EM, Tanaka H and Di Vizio D: Large extracellular vesicles carry most of the tumour DNA circulating in prostate cancer patient plasma. J Extracell Vesicles 7: 1505403, 2018. PMID: 30108686. DOI: 10.1080/20013078.2018.1505403

12 Liu MX, Liao J, Xie M, Gao ZK, Wang XH, Zhang Y, Shang MH, Yin LH, Pu YP and Liu R: miR-93-5p transferred by exosomes promotes the proliferation of esophageal cancer cells via intercellular communication by targeting PTEN. Biomed Environ Sci 31: 171-185, 2018. PMID: 29673440. DOI: $10.3967 /$ bes 2018.023

13 Gallerani G and Fabbri F: Circulating tumor cells in the adenocarcinoma of the esophagus. Int J Mol Sci 17: 1266, 2016 PMID: 27527155. DOI: 10.3390/ijms 17081266

14 Kuvendjiska J, Bronsert P, Martini V, Lang S, Pitman MB, Hoeppner $\mathrm{J}$ and Kulemann B: Non-metastatic esophageal adenocarcinoma. Circulating tumor cells in the course of multimodal tumor treatment. Cancers 11: 397, 2019. PMID: 30901891. DOI: 10.3390/cancers11030397

15 Pernot S, Badoual C, Terme M, Castan F, Cazes A, Bouche O, Bennouna J, Francois E, Ghiringhelli F, La Fouchardiere C de, 
Samalin E, Bachet JB, Borg C, Ducreux M, Marcheteau E, Stanbury T, Gourgou S, Malka D and Taieb J: Dynamic evaluation of circulating tumour cells in patients with advanced gastric and oesogastric junction adenocarcinoma. Prognostic value and early assessment of therapeutic effects. Eur J Cancer 79: 15-22, 2017. PMID: 28456090. DOI: 10.1016/j.ejca.2017.03.036

16 Woestemeier A, Ghadban T, Riethdorf S, Harms-Effenberger K, Konczalla L, Uzunoglu FG, Izbicki JR, Pantel K, Bockhorn M and Reeh M: Absence of HER2 expression of circulating tumor cells in patients with non-metastatic esophageal cancer. Anticancer Res 38: 5665-5669, 2018. PMID: 30275185. DOI: 10.21873 /anticanres. 12902

17 Adams DL, Martin SS, Alpaugh RK, Charpentier M, Tsai S, Bergan RC, Ogden IM, Catalona W, Chumsri S, Tang CM and Cristofanilli M: Circulating giant macrophages as a potential biomarker of solid tumors. Proc Natl Acad Sci U S A 111: 35143519, 2014. PMID: 24550495. DOI: 10.1073/pnas.1320198111

18 Sutton TL, Walker BS and Wong MH: Circulating hybrid cells join the fray of circulating cellular biomarkers. Cell Mol Gastroenterol Hepatol 8: 595-607, 2019. PMID: 31319228. DOI: 10.1016/j.jcmgh.2019.07.002

19 Mu Z, Wang C, Ye Z, Rossi G, Sun C, Li L, Zhu Z, Yang H and Cristofanilli M: Prognostic values of cancer associated macrophage-like cells (CAML) enumeration in metastatic breast cancer. Breast Cancer Res Treat 165: 733-741, 2017. PMID: 28687903. DOI: $10.1007 / \mathrm{s} 10549-017-4372-8$

20 Tang C-M, Zhu P, Li S, Makarova OV, Amstutz PT and Adams DL: Blood-based biopsies-clinical utility beyond circulating tumor cells. Cytometry A 93: 1246-1250, 2018. PMID: 30369050. DOI: $10.1002 /$ cyto.a.23573

21 Cappelletti V, Verzoni E, Ratta R, Vismara M, Silvestri M, Montone R, Miodini P, Reduzzi C, Claps M, Sepe P, Daidone MG and Procopio G: Analysis of single circulating tumor cells in renal cell carcinoma reveals phenotypic heterogeneity and genomic alterations related to progression. Int J Mol Sci 21, 2020. PMID: 32098246. DOI: 10.3390/ijms21041475

22 Keller L and Pantel K: Unravelling tumour heterogeneity by singlecell profiling of circulating tumour cells. Nat Rev Cancer 19: 553567, 2019. PMID: 31455893. DOI: 10.1038/s41568-019-0180-2

23 Nicolazzo C, Raimondi C, Gradilone A, Emiliani A, Zeuner A, Francescangeli F, Belardinilli F, Seminara P, Loreni F, Magri V, Tomao S and Gazzaniga P: Circulating Tumor cells in right- and left-sided colorectal cancer. Cancers 11: 1042, 2019. PMID: 31344798. DOI: $10.3390 /$ cancers 11081042

24 Aya-Bonilla CA, Morici M, Hong X, McEvoy AC, Sullivan RJ, Freeman J, Calapre L, Khattak MA, Meniawy T, Millward M, Ziman $\mathrm{M}$ and Gray ES: Detection and prognostic role of heterogeneous populations of melanoma circulating tumour cells. Br J Cancer 122: 1059-1067, 2020. PMID: 32037400. DOI: $10.1038 / \mathrm{s} 41416-020-0750-9$

25 Rosenbaum MW, Cauley CE, Kulemann B, Liss AS, Castillo CF-D, Warshaw AL, Lillemoe KD, Thayer SP and Pitman MB: Cytologic characteristics of circulating epithelioid cells in pancreatic disease. Cancer Cytopathol 125: 332-340, 2017. PMID: 28257167. DOI: $10.1002 /$ cncy.21841

26 Hofman VJ, Ilie MI, Bonnetaud C, Selva E, Long E, Molina T, Vignaud JM, Flejou JF, Lantuejoul S, Piaton E, Butori C, Mourad N, Poudenx M, Bahadoran P, Sibon S, Guevara N, Santini J, Venissac N, Mouroux J, Vielh P and Hofman PM: Cytopathologic detection of circulating tumor cells using the isolation by size of epithelial tumor cell method. Promises and pitfalls. Am J Clin Pathol 135: 146-156, 2011. PMID: 21173137. DOI: 10.1309/AJCP9X8OZBEIQVVI

27 Sobin LH, Gospodarowicz MK and Wittekind C (eds.). TNM Classification of Malignant Tumours. New York, NY, John Wiley \& Sons, 2011

28 Cheng B, Tong G, Wu X, Cai W, Li Z, Tong Z, He L, Yu S and Wang S: Enumeration and characterization of circulating tumor cells and its application in advanced gastric cancer. OncoTargets Ther 12: 7887-7896, 2019. PMID: 31576146. DOI: 10.2147/OTT.S223222

29 Giorgi V de, Pinzani P, Salvianti F, Panelos J, Paglierani M, Janowska A, Grazzini M, Wechsler J, Orlando C, Santucci M, Lotti T, Pazzagli M and Massi D: Application of a filtration- and isolation-by-size technique for the detection of circulating tumor cells in cutaneous melanoma. J Invest Dermatol 130: 2440-2447, 2010. PMID: 20535130. DOI: 10.1038/jid.2010.141

30 Krebs MG, Hou J-M, Sloane R, Lancashire L, Priest L, Nonaka D, Ward TH, Backen A, Clack G, Hughes A, Ranson M, Blackhall FH and Dive C: Analysis of circulating tumor cells in patients with non-small cell lung cancer using epithelial marker-dependent and -independent approaches. J Thorac Oncol 7: 306-315, 2012. PMID: 22173704. DOI: 10.1097/JTO.0b013e31823c5c16

31 Wang PP, Liu SH, Chen CT, Lv L, Li D, Liu QY, Liu GL and Wu Y: Circulating tumor cells as a new predictive and prognostic factor in patients with small cell lung cancer. J Cancer 11: 21132122, 2020. PMID: 32127938. DOI: 10.7150/jca.35308

32 Hou J, Guo C and Lyu G: Clinical significance of epithelialmesenchymal transition typing of circulating tumour cells in colorectal cancer. Colorectal Dis 22(5): 581-587, 2019. PMID: 31868956. DOI: $10.1111 /$ codi.14927

33 Wang L, Zhou S, Zhang W, Wang J, Wang M, Hu X, Liu F, Zhang Y, Jiang B and Yuan H: Circulating tumor cells as an independent prognostic factor in advanced colorectal cancer. A retrospective study in 121 patients. Int J Colorectal Dis 34: 589-597, 2019. PMID: 30627849. DOI: 10.1007/s00384-018-03223-9

34 Hou J, Zou K, Yang C, Leng X and Xu Y: Clinicopathological and prognostic significance of circulating tumor cells in patients with esophageal cancer. A meta-analysis. OncoTargets Ther 11: 8053 8061, 2018. PMID: 30519047. DOI: 10.2147/OTT.S175855

35 Han D, Chen K, Che J, Hang J and Li H: Detection of epithelialmesenchymal transition status of circulating tumor cells in patients with esophageal squamous carcinoma. BioMed Res Int 2018: 7610154, 2018. PMID: 30046606. DOI: 10.1155/2018/7610154

36 Wang D, Yang YC, Yao HW, Jin L, Wang J, Bai ZG and Zhang ZT: Detection and clinical significance of circulating tumor cells in patients with colorectal carcinoma. Zhonghua Wai Ke Za Zhi 55: 765-769, 2017. PMID: 29050178. DOI: 10.3760/cma.j.issn.05295815.2017.10.010

37 Yang Y, Li J, Jin L, Wang D, Zhang J, Wang J, Zhao X, Wu G, Yao $\mathrm{H}$ and Zhang $\mathrm{Z}$ : Independent correlation between Ki67 Index and circulating tumor cells in the diagnosis of colorectal cancer. Anticancer Res 37: 4693-4700, 2017. PMID: 28739773. DOI: $10.21873 /$ anticanres.11874

Received August 2, 2020

Revised September 6, 2020

Accepted September 7, 2020 